\title{
Surgical Reduction of Visceral versus Subcutaneous Fat and Effect on Features of the Metabolic Syndrome
}

\author{
Mahmoud Abdelaal ${ }^{1,2}$, Carel W le Roux ${ }^{1,3,4}$ and Neil G Docherty ${ }^{1,3 *}$ \\ ${ }^{1 * D i a b e t e s}$ Complications Research Centre, Conway Institute, School of Medicine and Medical Sciences, University College Dublin, Ireland \\ ${ }^{2}$ Plastic Surgery Department, Assiut University Hospital, Assiut, Egypt \\ ${ }^{3}$ Department of Gastrosurgical Research and Education, Institute of Clinical Sciences, Sahlgrenska Academy, University of Gothenburg, Sweden \\ ${ }^{4}$ Investigative Science, Imperial College London, UK \\ ${ }^{*}$ Correspondence to: Neil Docherty, Diabetes Complications Research Centre, Conway Institute, University College Dublin, Ireland, Tel: 0035317166877; \\ E-mail: neil.docherty@ucd.ie
}

Received: November 22, 2016; Accepted: December 07, 2016; Published: December 14, 2016;

\begin{abstract}
Background

Obesity results in both health and financial tolls for individuals and society. Despite the great efforts to increase awareness, the obesity epidemic continues at an alarming rate. Subcutaneous fat represents $85 \%$ of the fat mass in obese patients, while intra-abdominal fat, including both visceral and retroperitoneal adipose, represent about $15 \%$. Both subcutaneous and visceral fat have a negative effect on individual health and promote metabolic diseases. Logic would thus suggest that adipose tissue removal by liposuction and/or visceral tissue removal could effect an improvement in metabolic diseases such as Type 2 diabetes?
\end{abstract}

\section{Methods}

The scientific literature was searched to illustrate and describe the effect of adipose tissue on metabolism and the effect of its removal on inflammatory and metabolic markers.

\section{Results}

Adipose tissue is an endocrine organ and in obesity serves as a source of systemic proinflammatory signals arising from stressed adipocytes and/or infiltrating macrophages. These signals are associated with insulin resistance, dyslipidemia and hypertension (metabolic syndrome). The benefits of fat removal on metabolic syndrome remain controversial.

\section{Conclusion}

Visceral and subcutaneous fat is associated with high risk of coronary heart disease, insulin resistance, and other metabolic risk factors. Abdominal lipectomy is a well-known cosmetic procedure and used widely for its benefits on improving body image. However, its benefit on the metabolic disorder remains inconclusive. On the other hand, current evidence would suggest that omentectomy offers no benefit in relation to improvements in systemic inflammation and metabolic control. Removal of visceral adipose tissue in and of itself would thus appear to have limited efficacy as an approach to the treatment of the obesity-related metabolic syndrome.

Key words: Visceral and subcutaneous fat, Liposuction, Omentectomy, Metabolic Syndrome

\section{Introduction}

Obesity is defined as a systemic disease that shows excessive and abnormal accumulation of body fat leading to adverse health effects. Obesity has negative effects on health and exerts significant financial tolls on individuals and society. Despite significant efforts to increase awareness, the obesity epidemic continues at an alarming rate [1]. More than $50 \%$ of the European population is overweight and up to $30 \%$ is obese with prevalence worldwide doubling since 1980 [World Health Organization 2011] [2].

Abdominal obesity is defined as increased visceral fat and trunk subcutaneous fat which leads to increased waist circumference [3].
The contribution of abdominal subcutaneous fat mass and the visceral fat mass to the pathogenesis of metabolic disease is controversial, but it is associated with high risk of coronary heart disease, insulin resistance, and other metabolic risk factors [3, 4].

Subcutaneous fat represents $85 \%$ of the fat mass in obese patients, while intra-abdominal fat, including both visceral and retroperitoneal adipose, represent about $15 \%[5]$. Visceral obesity is presumed to predispose individuals to hepatic insulin resistance based on its anatomical site and venous drainage to the liver through the passage of adipocytes products into the portal vein[6-8]. 
Waist circumference [WC] and waist to hip circumference ratio [WHR] are used to measure abdominal obesity $[9,10]$, Body mass index [BMI] which equals the ratio of weight in kilograms divided by height in meters squared $[\mathrm{kg} / \mathrm{m} 2]$ is used to measure general obesity [11]. Each of these three parameters can be used to measure the association of obesity and metabolic risk factors, but the combination of the three [BMI, WC, and WHC] appears more useful than the use of BMI alone $[12,13]$.

Theoretically, WC cut-off results are $>88 \mathrm{~cm}$ in women and $>102$ $\mathrm{cm}$ in men but actually, it is difficult to apply in all populations due to the marked difference in the average levels of measurement. Asians are characterized by higher morbidity at lower cut-off for WC than other populations [14].

\section{The metabolic effects of visceral and subcutaneous adipose tissue}

Although body fat mass distribution is characterized by marked individual variations it can generally be classified into the following four types, a]Abdominal subcutaneous: most of the fat stored subcutaneously around the stomach and chest, b]Lower body: fat storage around the thighs, hip, and buttocks, c] Overall coverage: fat accumulation in the arms, breast, thighs, buttocks, lower back and breast, d] Visceral: fat deposition within visceral cavity surrounding the viscera including stomach, intestine, liver and pancreas [Figure 1] [15].
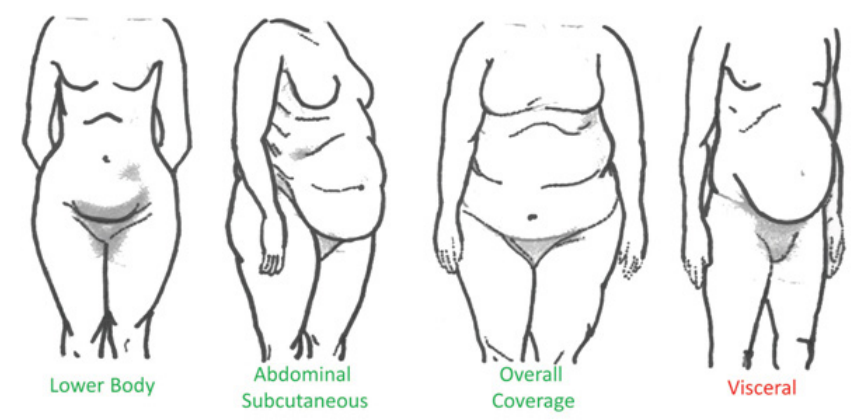

Figure 1. Types of body fat mass distribution[15]

More specifically, upper body fat distribution and increased visceral fat is more associated with metabolic dysregulation[16-18] than lower body and abdominal subcutaneous fat accumulation $[19,20]$. Metabolic disorders associated with subcutaneous and visceral obesity include insulin resistance, type 2 diabetes [21, 22], dyslipidemia [23], and hypertension [24, 25].

Adipose tissue is an endocrine organ producing proinflammatory molecules from adipocytes and/or infiltrating macrophages in patients with high BMI, WC, and WHC [26]. These include tumor necrosis factor-alpha [TNF- $\alpha$ ], C-reactive protein [CRP], interleukin-18 [IL18], and interleukin-6 [IL-6] [27-30]. These cytokines have been linked to impairments in insulin action in liver, muscle, and adipose tissue [31-33].

TNF- $\alpha$ in obesity is increased in both systemic and portal circulation [32], which affects insulin sensitivity within adipocytes and stimulates secretion of IL-6 [34] Also, IL-6 concentration is 50\% higher in the portal vein than in the peripheral circulation for patients with high visceral obesity [32].

Leptin and adiponectin expression is higher in subcutaneous fat compared with visceral adipose tissue $[35,36]$, but cytokine expression such as IL-6, IL-8 appears to be higher in visceral adipose tissue compared with subcutaneous fat [37].

Excess visceral and subcutaneous fat mass are associated with an elevation in postprandial [38] and post-absorptive fatty acid concentration in portal vein and systemic circulations [39]. Chronic exposure of the liver to the high concentration of free fatty acids promotes liver gluconeogenesis facilitating hepatic glucose production, thus providing a continuous source of energy and substrate that tends to raise fasting glycaemia $[8,40]$. Increased insulin resistance and reduced fatty acid oxidation increase fat storage and synthesis in the liver [41-43].

\section{Adipose tissue removal surgeries}

\section{Liposuction}

Liposuction is one of the most common plastic surgeries and aims to remove subcutaneous adipose tissue from different body areas so as to improve body image and create more physical balance [44]. Since its introduction by Illouz 30 years ago, its popularity has rapidly increased, making it the second most common cosmetic surgical procedure in 2012 [313,011 patients] [45]. nearly 400,000 procedures are performed annually in USA [45].

The removal of subcutaneous fat with a blunt cannula attached to a suction generating device was first popularized in Europe in the late 1970s. The procedure of liposuction has undergone many refinements and evolved with improvement in techniques and technology since its introduction by Illouz in 1982 [46-48].

\section{a) Traditional liposuction}

Liposuction was first practiced without any preparation of the fat before suctioning it from the subcutaneous tissue and this was called 'Dry liposuction' which was associated with a high incidence of hemorrhage and hematoma. Then Illouz developed the wet technique by injecting normal saline, water, and hyaluronidase to create a weak hypotonic solution to destroy the fat cell wall [49]. Hetter added lidocaine and dilute epinephrine to the injected solution [50], then the super wet and tumescent techniques were developed by injecting the standard wetting solution [ $1 \mathrm{ml}$ of epinephrine and $50 \mathrm{ml}$ of $1 \%$ xylocaine for each 1 liter of lactated Ringer solution] [51].

The ratio of the volume of wetting solution infused to the volume of fat aspirate is $1: 1$ in wet technique but 2 or 3:1 in the tumescent. Although, wetting and tumescent techniques are different in this ratio, they both involve infusion of the wetting solution to the point of tissue turgor or a "peau d'orange" of the overlying skin followed by suction of the subcutaneous tissue [51].

\section{b) Ultrasound-assisted liposuction[UAL]}

Zocchi is credited for the application of ultrasonic energy in liposuction to allow more selective tissue targeting [52]. It works by having expansion and compression parts of the cycle as a sound 
wave, which exerting a negative pressure that overcomes molecular forces results in cellular fragmentation with the intracellular content release, which leading to interstitial cavities hence termed as cavitation. Subsequently, a low-power suction can be performed [52, 53]. In this technique, sufficient amount of wetting solution must be used to limit the effect of heat generated by Us probe. Cellular disruption has been confirmed by the homogenous, macroscopically-acellular aspirated fat which contains a high level of adipocyte-specific intracellular glycerol 3-phosphate dehydrogenase isozyme [54]. UAL is highly efficient in removal of fat in fibrous areas such as the upper back, the hypogastrium, and the breast. UAL has been shown to cause less disruption of vasculature than SAL and hence less bruising [55].

\section{c) Power assisted liposuction [PAL $]$}

In the late 1990s, PAL was developed to subside some of UAL side effects. Actually,it is traditional liposuction with a special reciprocating cannula [Figure 2]. It is useful for fibrous rich areas liposuction and easy for the surgeon to use. No heat generation considers its main advantage over PAL [56].

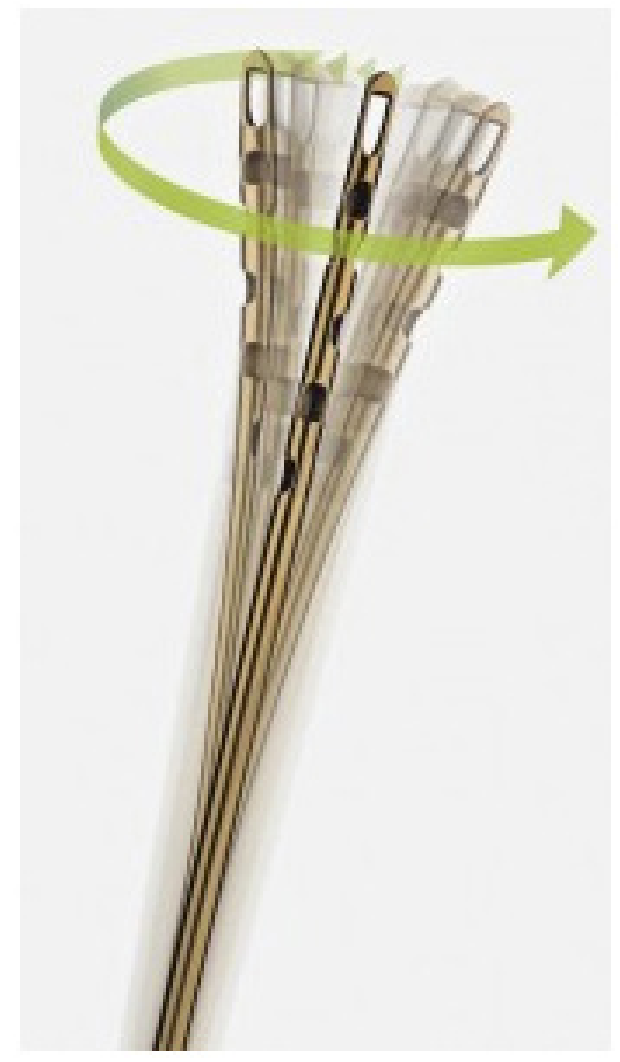

Figure 2. Power assisted liposuction cannula

\section{d) Laser-assisted liposuction [LAL]}

LAL is defined as, the simultaneous use of a bare laser fiber as a free beam or a confined beam to lyse, liquefy the fat while simultaneously coagulating small blood vessels at the cannula fat interface. Harness in 1990 described the use of $1064 \mathrm{~nm}$ Nd-YAG laser for liposuction with promising results such as minimal incision and skin contraction produced by its photothermal effect [47]. Recently, the use of 1,320-, 1,440- and 2,100-nm wavelengths also have been proposed, with claims of less bleeding, faster healing, and better tissue tightening using laser lipolysis [57-60].

\section{e) Radiofrequency-assisted liposuction [RFAL]}

Radiofrequency-assisted liposuction [RFAL] means usage of bipolar radiofrequency energy [similar to that of diathermy] to disrupt the fat cell membrane and facilitate lipolysis with a lesser requirement for suction power [61, 62]. A controlled subdermal thermal injury produced by this energy leads to healing by contraction which produces a secondary effect on skin contraction such as LAL [61]

\section{Omentectomy}

Omentectomy $[\mathrm{OM}]$ defined as, surgical removal of the whole greater omentum which is a thin fold of abdominal tissue that encases the stomach, large intestine, and other abdominal organs. There are two main types of omentectomy: completely removing the omentum which is called total or supra colic omentectomy and removing a portion of the omentum which refers to partial omentectomy.

The procedure may be performed traditionally or laparoscopically, the traditional approach involves mini-laparotomy with a median supraumbilical incision of 8 to $10 \mathrm{~cm}$ to release the omentum from the large gastric curvature while preserving the gastroepiploic artery [63].

Laparoscopic omentectomy technique: Four trocars are used to reach the abdominal cavity at the following positions, under the umbilicus, right lower quadrant, and two at left lower quadrant [63]. After inflation of the abdominal cavity, body and fundus of the stomach are released from the greater omentum and short gastric vessels by harmonic scalpel with remaining of gastroepiploic vessels intact. After detaching the omentum from the transverse colon pulled out through the infra-umbilical incision [64].

\section{Effect of adipose tissue removal on metabolic disease}

\section{Liposuction}

A study by Giugliano et al, examined the effect of subcutaneous fat suction on insulin resistance and vascular inflammatory markers in 30 obese women by comparing the pre and postoperative [6 months] HOMA [fasting plasma glucose [mmol/l] x fasting serum insulin $[\mathrm{mU} / \mathrm{ml}]$ divided by 25$]$ as an index of peripheral insulin resistance., High HOMA scores denote low insulin sensitivity. Levels of IL-6, IL-8, TNF- $\alpha$, CRP and adiponectin were also assessed. Results demonstrated that liposuction was associated with significant decrease in all parameters, except adiponectin, which significantly increased [Table 1] [65]. The risk of cardiovascular death and the incidence of insulin resistance was reduced at follow-up in association with improvements in metabolic and inflammatory markers.

In a study by Ramos et al, patients underwent abdominoplasty from October 2010 to September 2011. Total cholesterol, high-density lipoprotein $[\mathrm{HDL}]$, low-density lipoprotein $[\mathrm{LDL}]$, very low-density lipoprotein [VLDL], triglycerides, glucose, insulin, and HOMA index were measured preoperatively and 3 months post-operative. The results showed a significant reduction in triglyceride and LDL and a nonsignificant trend for improvements in HOMA, cholesterol,glucose, insulin and HDL[Table 2] [66]. The findings of this study were more 
or less similar to the Swanson study, which included 322 patients and demonstrated a significant reduction in triglycerides only [67].

Table 1. Results of Giugliano et al, study[65].

\begin{tabular}{|ll|c|c|c|}
\hline & Baseline & $\begin{array}{c}\text { Six months } \\
\text { postoperative }\end{array}$ & P-value \\
\hline Weight & & 88 & 85 & $<0.001$ \\
\hline HOMA & 4.1 & 3.08 & $<0.05$ \\
\hline IL-6 & $\mathrm{pg} / \mathrm{ml}$ & 4.1 & 3.2 & $<0.05$ \\
\hline IL-18 & $\mathrm{pg} / \mathrm{ml}$ & 246 & 219 & $<0.05$ \\
\hline TNF-a & $\mathrm{pg} / \mathrm{ml}$ & 5.1 & 4.1 & $<0.02$ \\
\hline CRP & $\mathrm{ml} / 1$ & 2.9 & 2.4 & $<0.02$ \\
\hline Adiponectin & $\mathrm{ug} / \mathrm{ml}$ & 5.1 & 6.4 & $<0.02$ \\
\hline
\end{tabular}

Table 2. Results of Ramos et al., study [66].

\begin{tabular}{|ll|c|c|c|}
\hline & & Baseline & $\begin{array}{c}\text { Three months } \\
\text { postoperative }\end{array}$ & P-value \\
\hline Weight & $\mathrm{kg}$ & 69.1 & 68.6 & 0.79 \\
\hline Glucose & $\mathrm{mg} / \mathrm{dl}$ & 91.45 & 90.71 & 0.81 \\
\hline Insulin & $\mathrm{Ul} / \mathrm{ml}$ & 17.11 & 11.79 & 0.28 \\
\hline HOMA & & 3.96 & 2.58 & 0.22 \\
\hline Cholesterol & $\mathrm{mg} / \mathrm{dl}$ & 224 & 220 & 0.84 \\
\hline Triglyceride & $\mathrm{mg} / \mathrm{dl}$ & 193 & 133 & 0.03 \\
\hline HDL & $\mathrm{mg} / \mathrm{dl}$ & 44 & 49 & 0.18 \\
\hline VLDL & $\mathrm{mg} / \mathrm{dl}$ & 43 & 39.1 & 0.55 \\
\hline LDL & $\mathrm{mg} / \mathrm{dl}$ & 137 & 79.61 & 0.04 \\
\hline
\end{tabular}

In the cohort study of Marfella et al, 20 patients underwent abdominoplasty and 28 patients were exposed to diet, exercise, and behavioral counseling. Authors compared preoperative and 2-month postoperative measurements of triglycerides, insulin, insulin sensitivity, IL-6, TNF- $\alpha$, and HDL-cholesterol. A significant reduction in triglycerides and insulin and improved insulin sensitivity was observed in both groups, with significant decreases in IL- 6 and TNF- $\alpha$ occurring only in abdominoplasty group. There were no changes in HDL-cholesterol during the study period [68]. In a prospective cohort study, 12 obese patients that underwent abdominoplasty were followed up and plasma triglycerides, HDL, cholesterol, and insulin sensitivity measured during the preoperative period and at 50 days postoperative [69]. In difference to other studies in the field, no improvements were observed in any of the parameters studied.

An overall survey of the literature suggests that on balance, besides the cosmetic results of liposuction, a positive impact on lipid profile and other metabolic markers can arise as a secondary benefit of the procedure. However diet, lifestyle, and exercise modification subsequent to liposuction are likely to significantly enhance the magnitude and duration of beneficial effects by preventing new fat deposition [66]. Whether liposuction can be advocated primarily for its metabolic effects remains however rather controversial and there is still an insufficient evidence base to support its use in this context.

\section{Omentectomy}

Fabbrini et al, conducted a randomized controlled trial to test the hypothesis of the effect of visceral fat removal on metabolic diseases.
Eleven patients underwent laparoscopic combined Roux-en-y [RYGB] with omentectomy, but RYGB alone was performed to the same number. Leptin, blood glucose, HbA1c, insulin, CRP, cholesterol, LDL, HDL, and triglyceride were measured preoperatively, 6 months and 12 months postoperative. Results of comparing pre and postoperative investigations demonstrated that hepatic insulin sensitivity increased 4-fold and skeletal muscle insulin sensitivity approximately doubled at 12 months after surgery in both groups, Critically no significant augmentation of improvements in these parameters was observed in patients undergoing omentectomy. So, metabolic variables improved after RYGB surgery but visceral fat removal has no additive effect on these variables . [70]. However, these data did not preclude the possibility that stand-alone omentectomy could be of metabolic benefit. To examine this, the same trial incorporated a treatment arim in which 10 patients underwent laparoscopic omentectomy alone. Results demonstrated that metabolic variables and minimal modelderived indices of insulin sensitivity, glucose effectiveness, and Betacell function did not change significantly 3 months after omentectomy compared with baseline [70].

Lima et al, and Herrera et al, are two prospective randomized trials looking at omentectomy[71, 72]. Both studies randomized patients equally into two groups, patients of the first group underwent RYGB with omentectomy but RYGB alone was performed to patients of the other group. Both studies used blood samples to measure metabolic and inflammatory markers for patients as in the study of Fabbrini and drew the same conclusions, i.e. omentectomy did not confer any additional benefit on top of RYGB.

From the previous studies and trials, it is thus clear that omentectomy does not induce any improvement in the components of metabolic syndrome and inflammatory mediators. Given the constitutive protective function of the omentum in the abdomen, there appears to be no basis for pursuing omentectomy as a viable intervention for metabolic disease.

\section{Conclusion}

Theoretically, increased visceral and subcutaneous adiposity are major risk factors for insulin resistance, dyslipidemia, and other metabolic disorders. Abdominal lipectomy is a well-known cosmetic procedure and used widely for its benefits on improving body image. However, its benefit on the metabolic disorder remains controversial. On the other hand, Omentectomy also does not induce any improvement in the components of inflammatory mediators but its effect on metabolic diseases considered an arguable issue. The currently available literature on visceral fat removal and liposuction are characterized by a small number of patients, we need more powerful randomly controlled trials to provide additional evidence. Intriguingly the fact that removal of subcutaneous rather than visceral fat, [at least the omentum] confers metabolic benefits, challenges current orthodoxy regarding the involvement of the two major fat depots in metabolic syndrome.

\section{References}

1. Mokdad AH, Ford ES, Bowman BA, Dietz WH, Vinicor F, et al. (2003) Prevalence of obesity, diabetes, and obesity-related health risk factors, 2001. JAMA 289: 76-79. [crossref] 
2. Lee WJ, Yu PJ, Wang W, Chen TC, Wei PL, et al. (2005) Laparoscopic Rouxen-Y versus mini-gastric bypass for the treatment of morbid obesity: a prospective randomized controlled clinical trial. Ann Surg 242: 20-28. [crossref]

3. Kissebah AH, Vydelingum N, Murray R, Evans DJ, Hartz AJ, et al. (1982) Relation of body fat distribution to metabolic complications of obesity. J Clin Endocrinol Metab 54: 254-260. [crossref]

4. Abate N, Garg A, Peshock RM, Stray-Gundersen J, Grundy SM (1995) Relationships of generalized and regional adiposity to insulin sensitivity in men. $J$ Clin Invest 96: 88-98. [crossref]

5. Klein S, Allison DB, Heymsfield SB, Kelley DE, et al. (2007) Waist Circumference and Cardiometabolic Risk: a Consensus Statement from Shaping America's Health: Association for Weight Management and Obesity Prevention; NAASO, the Obesity Society; the American Society for Nutrition; and the American Diabetes Association. Obesity 15:1061-7.

6. Hotamisligil GS, Peraldi P, Budavari A, Ellis R, et al. (1996) IRS-1-mediated inhibition of insulin receptor tyrosine kinase activity in TNF-alpha- and obesityinduced insulin resistance. Science 271:665-8.

7. Korec R (2001) --to: Bergman RN (2000) non-esterified fatty acids and the liver: why is insulin secreted into the portal vein? Diabetologia 43: 946-952. Diabetologia 44: 784. [crossref]

8. Williamson JR, Kreisberg RA, Felts PW (1966) Mechanism for the stimulation of gluconeogenesis by fatty acids in perfused rat liver. Proc Natl Acad Sci U S A 56: 247-254. [crossref]

9. Ardern CI, Katzmarzyk PT, Janssen I, Ross R (2003) Discrimination of health risk by combined body mass index and waist circumference. Obes Res 11: 135-142. [crossref]

10. Meisinger C, Döring A, Thorand B, Heier M, Löwel H (2006) Body fat distribution and risk of type 2 diabetes in the general population: are there differences between men and women? The MONICA/KORA Augsburg cohort study. Am J Clin Nutr 84: 483-489. [crossref]

11. [No authors listed] (2000) Obesity: preventing and managing the global epidemic. Report of a WHO consultation. World Health Organ Tech Rep Ser 894: i-xii, 1-253. [crossref]

12. Wang Y, Rimm EB, Stampfer MJ, Willett WC, Hu FB (2005) Comparison of abdominal adiposity and overall obesity in predicting risk of type 2 diabetes among men. Am J Clin Nutr 81: 555-563. [crossref]

13. Després JP, Lemieux I (2006) Abdominal obesity and metabolic syndrome. Nature 444: 881-887. [crossref]

14. Misra A, Vikram NK, Gupta R, Pandey RM, et al. (2006) Waist circumference cutoff points and action levels for Asian Indians for identification of abdominal obesity. Int J Obes (Lond) 30: 106-11.

15. Foster MT, Pagliassotti MJ (2012) Metabolic alterations following visceral fat removal and expansion: Beyond anatomic location. Adipocyte 1:192-9.

16. Björntorp P (1991) Metabolic implications of body fat distribution. Diabetes Care 14: 1132-1143. [crossref]

17. Kissebah AH, Krakower GR (1994) Regional adiposity and morbidity. Physiol Rev 74: 761-811. [crossref]

18. Bjorntorp P (1990) "Portal" adipose tissue as a generator of risk factors for cardiovascular disease and diabetes. Arteriosclerosis 10: 493-6.

19. Cefalu WT, Wang ZQ, Werbel S, Bell-Farrow A, Crouse JR 3rd, et al. (1995) Contribution of visceral fat mass to the insulin resistance of aging. Metabolism 44: 954-959. [crossref]

20. Kuk JL, Katzmarzyk PT, Nichaman MZ, Church TS, Blair SN, et al. (2006) Visceral fat is an independent predictor of all-cause mortality in men. Obesity (Silver Spring) 14: 336-341. [crossref]

21. Carey VJ, Walters EE, Colditz GA, Solomon CG, Willett WC, et al. (1997) Body fat distribution and risk of non-insulin-dependent diabetes mellitus in women. The Nurses' Health Study. Am J Epidemiol 145: 614-619. [crossref]

22. Chan JM, Rimm EB, Colditz GA, Stampfer MJ, Willett WC (1994) Obesity, fat distribution, and weight gain as risk factors for clinical diabetes in men. Diabetes Care 17: 961-969. [crossref]

23. Kissebah AH, Alfarsi S, Adams PW, Wynn V. Role of insulin resistance in adipose tissue and liver in the pathogenesis of endogenous hypertriglyceridaemia in man. Diabetologia 12: 563-71.

24. Cassano PA, Segal MR, Vokonas PS, Weiss ST (1990) Body fat distribution, blood pressure, and hypertension. A prospective cohort study of men in the normative aging study. Ann Epidemiol 1: 33-48. [crossref]

25. Seidell JC, Cigolini M, Deslypere JP, Charzewska J, Ellsinger BM, et al. (1991) Body fat distribution in relation to serum lipids and blood pressure in 38-year-old European men: the European fat distribution study. Atherosclerosis 86: 251-260. [crossref]

26. Weisberg SP, McCann D, Desai M, Rosenbaum M, Leibel RL, et al. (2003) Obesity is associated with macrophage accumulation in adipose tissue. J Clin Invest 112: 1796-1808. [crossref]

27. Bastard JP, Jardel C, Bruckert E, Blondy P, et al. (2007) Elevated levels of interleukin 6 are reduced in serum and subcutaneous adipose tissue of obese women after weight loss. J Clin Endocrinol Metab 85: 3338-42.
28. Ziccardi P, Nappo F, Giugliano G, Esposito K, et al. (2002) Reduction of inflammatory cytokine concentrations and improvement of endothelial functions in obese women after weight loss over one year. Circulation 105: 804-9.

29. Esposito K, Pontillo A, Ciotola M, Di Palo C, Grella E, et al. (2002) Weight loss reduces interleukin-18 levels in obese women. J Clin Endocrinol Metab 87: 3864 3866. [crossref]

30. Yudkin JS, Stehouwer CD, Emeis JJ, Coppack SW (1999) C-reactive protein in healthy subjects: associations with obesity, insulin resistance, and endothelial dysfunction: a potential role for cytokines originating from adipose tissue? Arterioscler Thromb Vasc Biol 19: 972-8.

31. Fernandez-Veledo S, Nieto-Vazquez I, Vila-Bedmar R, Garcia-Guerra L, et al (2009) Molecular mechanisms involved in obesity-associated insulin resistance: therapeutical approach. Arch Physiol Biochem 115: 227-39.

32. Fontana L, Eagon JC, Trujillo ME, Scherer PE, Klein S (2007) Visceral fat adipokine secretion is associated with systemic inflammation in obese humans. Diabetes 56: 1010-1013. [crossref]

33. Hoene M, Weigert C (2008) The role of interleukin-6 in insulin resistance, body fat distribution and energy balance. Obes Rev 9: 20-29. [crossref]

34. Sethi JK, Hotamisligil GS (1999) The role of TNF alpha in adipocyte metabolism. Semin Cell Dev Biol 10: 19-29. [crossref]

35. Fain JN, Madan AK, Hiler ML, Cheema P, et al. (2004) Comparison of the release of adipokines by adipose tissue, adipose tissue matrix, and adipocytes from visceral and subcutaneous abdominal adipose tissues of obese humans. Endocrinology 145 : 2273-82.

36. Van Harmelen V, Reynisdottir S, Eriksson P, Thörne A, Hoffstedt J, et al. (1998) Leptin secretion from subcutaneous and visceral adipose tissue in women. Diabetes 47: 913-917. [crossref]

37. Mirza MS (2011) Obesity, Visceral Fat, and NAFLD: Querying the Role of Adipokines in the Progression of Nonalcoholic Fatty Liver Disease. ISRN Gastroenterol 2011: 592404. [crossref]

38. Roust LR, Jensen MD (1993) Postprandial free fatty acid kinetics are abnormal in upper body obesity. Diabetes 42: 1567-1573. [crossref]

39. Jensen MD, Haymond MW, Rizza RA, Cryer PE, Miles JM (1989) Influence of body fat distribution on free fatty acid metabolism in obesity. $J$ Clin Invest 83 : 1168-1173. [crossref]

40. Williamson JR (1966) Mechanism for the stimulation in vivo of hepatic gluconeogenesis by glucagon. Biochem J 101: 11C-14C. [crossref]

41. Xu J, Nakamura MT, Cho HP, Clarke SD (1999) Sterol regulatory element binding protein-1 expression is suppressed by dietary polyunsaturated fatty acids. A mechanism for the coordinate suppression of lipogenic genes by polyunsaturated fats. J Biol Chem 274: 23577-83.

42. Insulin resistance induced by chronic high-fat feeding. Diabetes 46: 1768-1774. [crossref]

43. Boden G1 (1997) Role of fatty acids in the pathogenesis of insulin resistance and NIDDM. Diabetes 46: 3-10. [crossref]

44. Shridharani SM, Broyles JM2, Matarasso A1 (2014) Liposuction devices: technology update. Med Devices (Auckl) 7: 241-251. [crossref]

45. No authors listed] (2013) Cosmetic surgery National Data Bank: statistics 2012. Aesthet Surg J 33: 1S-21S. [crossref]

46. Lewis CM. Early history of lipoplasty in the United States. Aesthetic Plast Surg. 1990;14(2):123-6.

47. Apfelberg DB, Rosenthal S, Hunstad JP, Achauer B, Fodor PB (1994) Progress report on multicenter study of laser-assisted liposuction. Aesthetic Plast Surg 18: 259-264. [crossref]

48. Jewell ML, Fodor PB, de Souza Pinto EB, Al Shammari MA. Clinical application of VASER--assisted lipoplasty: a pilot clinical study. Aesthet Surg J 22:131-46.

49. Dolsky RL (1984) Body sculpturing by lipo-suction extraction. Aesthetic Plast Surg 8: 75-83. [crossref]

50. Hetter GP (1984) The effect of low-dose epinephrine on the hematocrit drop following lipolysis. Aesthetic Plast Surg 8: 19-21. [crossref]

51. Gingrass MK (2000) Ultrasound-Assisted Lipectomy Using the Solid Probe: A Retrospective Review of 100 Consecutive Cases. Plast Reconstr Surg 105: 2175-7.

52. Zocchi M (1992) Ultrasonic liposculpturing. Aesthetic Plast Surg 16: 287-298. [crossref]

53. Zocchi ML (1996) Ultrasonic assisted lipoplasty. Technical refinements and clinical evaluations. Clin Plast Surg 23: 575-98.

54. Rohrich RJ, Morales DE, Krueger JE, Ansari M, et al. (2000) Comparative lipoplasty analysis of in vivo-treated adipose tissue. Plast Reconstr Surg 105: 2152-8; discussion 9-60

55. Kenkel JM, Robinson JB Jr, Beran SJ, Tan J, Howard BK, et al. (1998) The tissue effects of ultrasound-assisted lipoplasty. Plast Reconstr Surg 102: 213-220. [crossref]

56. Ablaza VJ, Gingrass MK, Perry LC, Fisher J, et al. (1998) Tissue temperatures during ultrasound-assisted lipoplasty. Plast Reconstr Surg 102: 534-42.

57. Mordon S, Blanchemaison P (2008) "Histologic evaluation of interstitial lipolysis comparing a 1064, 1320 and $2100 \mathrm{~nm}$ laser in an ex vivo model" Lasers Surg Med 40: 519 . 
58. DiBernardo BE, Reyes J, Chen B (2009) Evaluation of tissue thermal effects from 1064/1320-nm laser-assisted lipolysis and its clinical implications. J Cosmet Laser Ther 11: 62-9.

59. Wassmer B, Zemmouri J, Rochon P, Mordon S (2010) Comparative study of wavelengths for laser lipolysis. Photomed Laser Surg 28: 185-188. [crossref]

60. Katz B, McBean J (2008) Laser-assisted lipolysis: a report on complications. $J$ Cosmet Laser Ther 10: 231-233. [crossref]

61. Paul M, Mulholland RS (2009) A new approach for adipose tissue treatment and body contouring using radiofrequency-assisted liposuction. Aesthetic Plast Surg 33: 687-94.

62. Blugerman G, Schavelzon D, Paul MD (2010) A safety and feasibility study of a novel radiofrequency-assisted liposuction technique. Plast Reconstr Surg 125 998-1006.

63. Milleo FQ, Campos AC, Santoro S, Lacombe A, et al. (2011) Metabolic effects of an entero-omentectomy in mildly obese type 2 diabetes mellitus patients after three years. Clinics (Sao Paulo) 66: 1227-33.

64. Santoro S, Velhote MC, Malzoni CE, Milleo FQ, et al. (2006) Preliminary results from digestive adaptation: a new surgical proposal for treating obesity, based on physiology and evolution. Sao Paulo Med J 124: 192-7.

65. Giugliano G, Nicoletti G, Grella E, Giugliano F, et al. (2004) Effect of liposuction on insulin resistance and vascular inflammatory markers in obese women. $\mathrm{Br} J$ Plast Surg 57: 190-4.
66. Ramos-Gallardo G, Pérez Verdin A, Fuentes M, Godínez Gutiérrez S, AmbrizPlascencia AR, et al. (2013) Effect of abdominoplasty in the lipid profile of patients with dyslipidemia. Plast Surg Int 2013: 861348. [crossref]

67. Swanson E (2011) Prospective clinical study reveals significant reduction in triglyceride level and white blood cell count after liposuction and abdominoplasty and no change in cholesterol levels. Plast Reconstr Surg 128:182e-97e.

68. Marfella R, Grella R, Rizzo MR, Barbieri M, et al. (2011) Role of subcutaneous abdominal fat on cardiac function and proinflammatory cytokines in premenopausal obese women. Ann Plast Surg 63: 490-5.

69. Martinez-Abundis E, Molina-Villa CA, Gonzalez-Ortiz M, Robles-Cervantes JA, et al. (2007) Effect of surgically removing subcutaneous fat by abdominoplasty on leptin concentrations and insulin sensitivity. Ann Plast Surg 58: 416-9.

70. Fabbrini E, Tamboli RA, Magkos F, Marks-Shulman PA, et al. (2010) Surgical removal of omental fat does not improve insulin sensitivity and cardiovascular risk factors in obese adults. Gastroenterology 139: 448-55.

71. Herrera MF, Pantoja JP, Velazquez-Fernandez D, Cabiedes J, et al. (2010) Potentia additional effect of omentectomy on metabolic syndrome, acute-phase reactants, and inflammatory mediators in grade III obese patients undergoing laparoscopic Roux-en-Y gastric bypass: a randomized trial. Diabetes Care 33: 1413-8.

72. Lima MM, Pareja JC, Alegre SM, Geloneze SR, et al. (2013) Visceral fat resection in humans: effect on insulin sensitivity, beta-cell function, adipokines, and inflammatory markers. Obesity (Silver Spring) 21: E182-9.

Citation:

Mahmoud Abdelaal, Carel W le Rouxand Neil G Docherty (2016) Surgical Reduction of Visceral versus Subcutaneous Fat and Effect on Features of the Metabolic Syndrome. Internal Med Res Open J Volume 1(2): 1-6 